\title{
Gamma $_{2}$, Gamma $_{1 \mathrm{~A}}$, and Gamma ${ }_{1 \mathrm{M}}$ Antinuclear Factors in Human Sera *
}

\author{
Eugene V. Barnett, $\dagger$ John J. Condemi, John P. Leddy, and \\ JoHN H. Vaughan \\ (From the Departments of Medicine and Microbiology, University of Rochester School of \\ Medicine and Dentistry, and the Rochester General and Strong Memorial \\ Hospitals, Rochester, N. Y.)
}

The term "immunoglobulin" is used to refer to one or more of the three classes of serum protein, gamma $_{1 \mathbf{A}}$, gamma $_{1 \mathbf{M}}$, and gamma 2 , each of which is known to contain antibodies. The $\gamma_{1 \mathbf{A}^{-}}$and $\gamma_{1 \mathrm{M}^{-}}$ immunoglobulins have also been referred to as beta $_{2 \Lambda}$ and beta $2 \mathrm{M}$, their electrophoretic mobilities being intermediate between the principal gamma and beta peaks in serum protein electrophoresis. $\gamma_{1 \mathrm{~A}}$-globulin, like $\gamma_{2}$-globulin, is approximately $7 \mathrm{~S}$ in its ultracentrifugal characteristics, but differs significantly from $\gamma_{2}$-globulin by other chemical and immunochemical criteria. $\gamma_{1 \mathrm{M}}$-globulin is a macro-gamma globulin that has an ultracentrifugation sedimentation coefficient of approximately $19 \mathrm{~S}$.

Determination of the immunochemical class of globulins responsible for the various autoreactivities found in various diseases may be important for our better understanding of the mechanisms of disease. The antinuclear factors (ANF), which are apparently autoantibodies to nuclear constituents, are found in the sera of patients with systemic lupus erythematosus (LE) and less frequently in other so-called connective tissue diseases, particularly rheumatoid arthritis (RA). Goodman, Fahey, and Malmgren (1) characterized ANF in two LE sera as globulins of both $7 \mathrm{~S}$ and $19 \mathrm{~S}$ type. Baum and Ziff (2) showed that ANF in LE sera were eluted from DEAE cellulose both

* Submitted for publication December 2, 1963; accepted January 30, 1964.

Presented in part before the Meeting of the American Rheumatism Association, Atlantic City, N. J., June 1963.

Aided by the grants from the National Institutes of Health (AI 02349-07) and the National Foundation (CRMS 202).

$\dagger$ Postdoctoral fellow of the Arthritis and Rheumatism Foundation. Address reprint requests to Dr. Barnett at the Rochester General Hospital, 501 Main Street West, Rochester 8, N. Y. at $\mathrm{pH} 7.0,0.01 \mathrm{M}$ phosphate, and at $\mathrm{pH} 5,0.3 \mathrm{M}$ phosphate, corresponding to the distribution of $7 \mathrm{~S}$ and $19 \mathrm{~S}$ globulins. Their data suggest that LE patients tended to have ANF of $\gamma_{2}(7 \mathrm{~S})$ class, whereas RA patients tended to have ANF of $\gamma_{1 \mathrm{M}}$ (19 S) class.

Our work, employing different techniques, was designed not only to compare LE and RA patients on the basis of their $\gamma_{2}$ and $\gamma_{1 M}$ ANF but, in addition, to investigate the incidence of $\mathrm{ANF}$ in the more newly described $\gamma_{1 \mathrm{~A}}$ class of globulins. In vivo tests have suggested that human atopic reagins are $\gamma_{1 \mathbf{A}}$-immunoglobulins (3). Anti-insulin (4), anti-Brucella (5), antidiptheria (5), and antiragweed antibodies (6) have recently been described in all three immunoglobulin classes.

\section{Methods}

A modification of the two-layer indirect ANF test (7) was employed. Three separate air-dried slides of human peripheral blood were fixed in $95 \%$ ethanol and used as a source of nuclear material. The patient's serum or a fraction of the patient's serum was overlaid for 30 minutes at room temperature. Then the slides were washed with phosphate buffered saline, $\mathrm{pH} 7$, for 30 minutes. In the two-layer indirect ANF test, a fluorescein-conjugated rabbit antiserum against human $\gamma$-globulins would be applied for 30 minutes, the slides then washed, mounted in glycerol-saline, and then examined with a fluorescent microscope. In the present test a rabbit serum against one of the three human immunoglobulins (i.e., anti- $\gamma_{2}$, anti- $\gamma_{1 \mathbf{A}}$, or anti- $\gamma_{1 \mathbf{M}}$ ) was applied for 30 minutes as the second layer to each of the three slides. The slides were washed again and then goat antirabbit globulin, conjugated with fluorescein isothiocyanate, was applied as the third layer. After 30 minutes the slides were again washed and then mounted in 90\% glycerol-saline with glass cover slips. Appropriate control slides were included in each test to rule out nonspecific adsorption of the rabbit or goat sera to human leukocytes. For quantitation of ANF, serial fourfold dilutions of the patient's serum were used instead 
of the patient's undiluted serum in the first layer. The titer of ANF of each immunoglobulin class was the highest dilution of the patient's serum giving nuclear fluorescence with a constant amount of specific rabbit and goat sera. The slides were read with a Zeiss-fluorescent microscope, ultraviolet light source, H B O 200 watt (Osram), exciting filter, $420 \mathrm{~m} \mu \mathrm{BG} \mathrm{12,} \mathrm{blocking} \mathrm{filter,}$ $500 \mathrm{~m} \mu$.

Antisera. Undiluted specific rabbit antisera against human $\gamma_{2^{-}}, \gamma_{1 \mathbf{1}^{-}}$, and $\boldsymbol{\gamma}_{1 \mathbf{1}}$-immunoglobulins were shown after appropriate absorption to react in immunodiffusion tests only with the homologous human serum globulins (8). In passive cutaneous anaphylaxis in guinea pigs and in hemagglutination tests, $1: 10$ dilution of the sera detected only the homologous globulins; lesser dilutions were not tried (8). In the current immunofluorescent studies these sera were used in $1: 20$ dilutions. Goat antirabbit serum was obtained from a single goat after multiple immunizations with Pentex Fraction II ${ }^{1}$ of rabbit globulins and whole rabbit serum in Freund's complete adjuvant. The goat antiserum was fractionated by precipitation in half-saturated ammonium sulfate and conjugated with fluorescein isothiocyanate (7). The goat antirabbit globulin conjugate was absorbed with acetonedried human spleen powder, whole fresh human serum, and human Fraction II, so that it gave no precipitate with human sera in double diffusion in agar gel and would not directly detect human ANF on leukocyte nuclei, i.e., in the absence of a rabbit antihuman serumimmunoglobulin as an intermediate layer.

Antigens. $\quad \gamma_{2^{-}}, \gamma_{1 \Lambda^{-}}$, and $\gamma_{1 \mathbf{m}}$-immunoglobulins were prepared from human sera (8). On immunoelectrophoresis using an anti-whole human serum in the antiserum wells, they gave only one line in the expected locations.

These purified rabbit antisera and purified human immunoglobulins were used in absorption and blocking experiments designed to demonstrate the specificity of the specific rabbit antisera used in the three-layer ANF test. In absorption studies, serial additions of specific rabbit antisera to a patient's serum were shown to remove only the corresponding class of immunoglobulin ANF. For instance, the addition of antisera specific for $\gamma_{2^{-}}$and $\gamma_{1 M}$ immunoglobulins resulted in the absorption of ANF of both $\gamma_{2}$ and $\gamma_{1 M}$ classes, but $\gamma_{1 \mathbf{A}}$ ANF was still present. In the blocking experiments, the addition of purified human $\gamma_{2}$-globulin to the rabbit anti- $\gamma_{2}$ sera blocked the detection of $\gamma_{2}$ ANF, whereas the addition of $\gamma_{\mathbf{I A}^{-}}$or $\gamma_{\mathbf{1 M}^{-}}$ globulins did not. Analogous specificity was demonstrated in blocking experiments for the anti- $\gamma_{1 \Delta}$ and anti- $\gamma_{1 M}$ rabbit sera.

Chromatography. Three LE sera were fractionated by DEAE cellulose column chromatography with start-

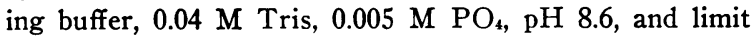
buffer $0.5 \mathrm{M}$ Tris, $0.5 \mathrm{M} \mathrm{PO}_{4}, \mathrm{pH} 5.5$, using a Varigrad as described by Riesfeld, Bergenstal, and Hertz (9).

Ultracentrifugation. Sera from four LE and one RA patient were fractionated by ultracentrifugation in a su-

\footnotetext{
1 Pentex Inc., Kankakee, III.
}

crose gradient (10). One-half $\mathrm{ml}$ of a $1: 4$ dilution of the patient's serum in $10 \%$ sucrose was layered on top of the sucrose gradient solution. The tubes were spun for 16 to 20 hours at $25,000 \mathrm{rpm}$ in the SW39L rotor head, Spinco model $\mathrm{L}$ centrifuge. The fractions were collected as previously described (11), six from above and three from below. The optical densities of each fraction read at $277 \mathrm{~m} \mu$ were recorded. One tube in each centrifugal run contained Evans blue dye, an incomplete anti-D serum, and rheumatoid factor as markers for albumin, $7 \mathrm{~S}$ and $19 \mathrm{~S}$ globulins, respectively. Each fraction was examined for the presence of $\gamma_{2^{-}}, \gamma_{1^{-}}$, or $\gamma_{1 \mathbf{M}}$-globulins in double diffusion using the specific rabbit antisera against the immunoglobulins.

Sulfhydryl sensitivity. Samples of five LE sera and one RA serum were diluted $1: 8$ in $0.1 \mathrm{M}$ mercaptoethanol or in saline and kept at $20^{\circ} \mathrm{C}$ for 24 hours (12) After dialysis to remove residual mercaptoethanol the treated and control serum specimens were then diluted and tested for ANF in the three-layer test.

Enzyme treatment. Glass slides of peripheral blood smears were incubated for 3 minutes at $20^{\circ} \mathrm{C}$ with $0.1 \%$ solutions of DNAse, RNAse, or trypsin. ${ }^{2}$ The control slides were incubated in $\mathrm{PO}_{4}-\mathrm{CO}_{3}$ buffer (13). These enzyme-treated or control leukocytes were then used in the three-layer test to determine if the reactivity of the nuclear material was eliminated by enzyme treatment. Sera from $6 \mathrm{RA}, 1$ juvenile RA, and $3 \mathrm{LE}$ patients were tested on these enzyme-treated slides to show the specificity of their ANF for enzyme-sensitive nuclear material.

$L E$ cell preparations. Patients' bloods were defibrinated by shaking with glass beads (14). After 2 hours of incubation at $20^{\circ} \mathrm{C}$, smears of the buffy coat were made and stained with Wright's stain. Each LE cell preparation was examined for 20 minutes at $100 \times$ magnification. In all patients studied all LE cell preparations were obtained at the time of or within 1 week of obtaining blood specimens for study by the ANF test.

Diagnostic criteria for $R A$ and $L E$. The patients with RA in the present study all had definite or classical RA, by the diagnostic criteria of the American Rheumatism Association (15) and Steinbrocker's system of functional classification and anatomical staging (16). All patients with a diagnosis of LE had positive LE cell preparations at some time during their illness, with one or more of the following signs: fever, rash, serositis, migratory polyarthritis, renal disease, thrombocytopenia, or anemia (15). None of the LE patients had joint deformities, rheumatoid nodules, or erosion of cartilage on radiologic examination.

\section{Results}

LE and RA sera were found to have ANF of one, two, or most often all three immunoglobulin classes. Nuclei that were either solidly fluorescent or rimmed (Figure 1) denoted a positive

\footnotetext{
2 Worthington Biochemical Corp., Freehold, N. J.
} 
ANF test, whereas only background staining of the leukocyte cytoplasm was seen when the test serum contained no detectable amounts of ANF.

\section{Chromatographic studies}

Three LE sera were fractionated by DEAE cellulose column chromatography. ANF of $\gamma_{2}$, $\gamma_{1 \mathbf{A}}$, and $\gamma_{1 \mathrm{M}}$ classes were detected in those eluates expected to contain each of these immunoglobulins (17-19). A single chromatogram is shown in Figure 2. The $\gamma_{1 \mathrm{~A}}$ ANF was not eluted without $\gamma_{1 \mathrm{M}}$ ANF with the particular gradient used. Chromatographic separation of two other LE sera gave similar results.

Sulfhydryl sensitivity and sedimentation characteristics

1. Gamma ${ }_{2}$ and gamma IM $_{1 M} A N$. The antibody activity of $\gamma_{2}$-globulins is not destroyed by incubation with $0.1 \mathrm{M}$ mercaptoethanol, whereas that of $\gamma_{1 \mathrm{M}}$-globulins is (12). Figure 3 demonstrates the sensitivity to inactivation by mercaptoethanol of ANF of the three immunoglobulin classes in five LE and three RA sera. The titers of $\gamma_{1 \mathrm{M}}$ ANF were reduced at least 16-fold in all cases. The titers of $\gamma_{2}$ were not reduced in any instances. ANF detected by mono specific anti- $\gamma_{2}$ antisera consistently sedimented as $7 \mathrm{~S}$ globulins, whereas $\gamma_{1 \mathrm{M}} \mathrm{ANF}$ sedimented as $19 \mathrm{~S}$ globulins (Table I).

2. Gamma ${ }_{1 A} A N F$. Titers of $\gamma_{1 \mathrm{~A}}$ ANF were reduced completely in two instances, partially in four, and none in two (Figure 3). In sera from Patients $\mathrm{K}$ and $\mathrm{L}_{1}$ the $\gamma_{1 \mathrm{~A}}$ ANF sedimented as $7 \mathrm{~S}$ globulins, whereas in sera $S_{1}, D$, and $E$ the $\gamma_{1 A}$ ANF appeared at least in part to sediment faster than did $\gamma_{2}$ ANF (Table I). These data suggest that $\gamma_{1 \mathrm{~A}}$ antibody may be quite heterogenous in regard to its sedimentation characteristics. Furthermore, the sedimentation characteristics of $\gamma_{1 \mathbf{A}}$ ANF in particular sera were found to cor-

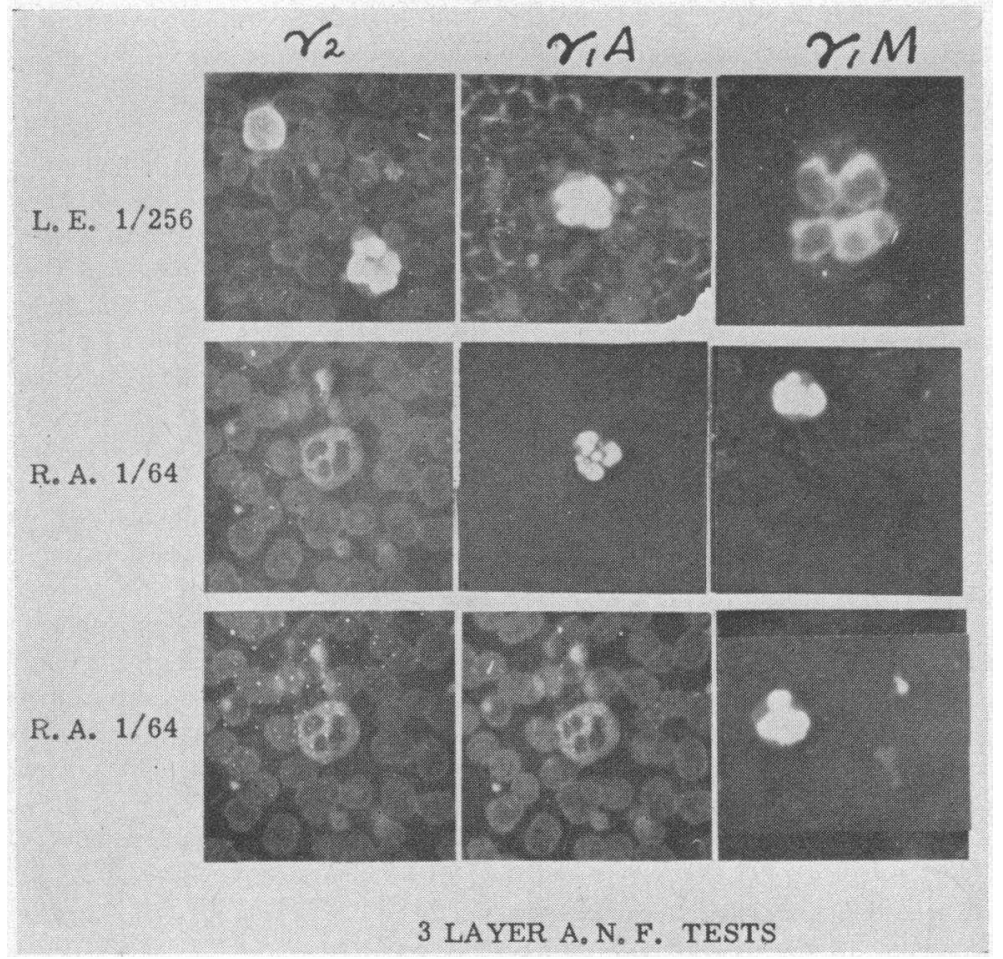

Fig. 1. Result of typical three-layer antinuclear factor (ANF) TEST ON DILUTION OF LUPUS ERYTHEMATOSUS (LE) AND RHEUMATOID ARTHRITIS (RA) SERA. Fluorescent nuclei either solidly fluorescent or rimmed denote a positive test. The LE serum is shown to have ANF of $\gamma_{2^{-}} \gamma_{1 A^{-}}$, and $\gamma_{1 M^{-}}$-immunoglobulin classes in titer of $1: 256$ or greater. The RA sera diluted 1:64 contain $\gamma_{1 \Delta}$ and $\gamma_{1 M}$ ANF in one case and only $\gamma_{1 M}$ ANF in the other. 


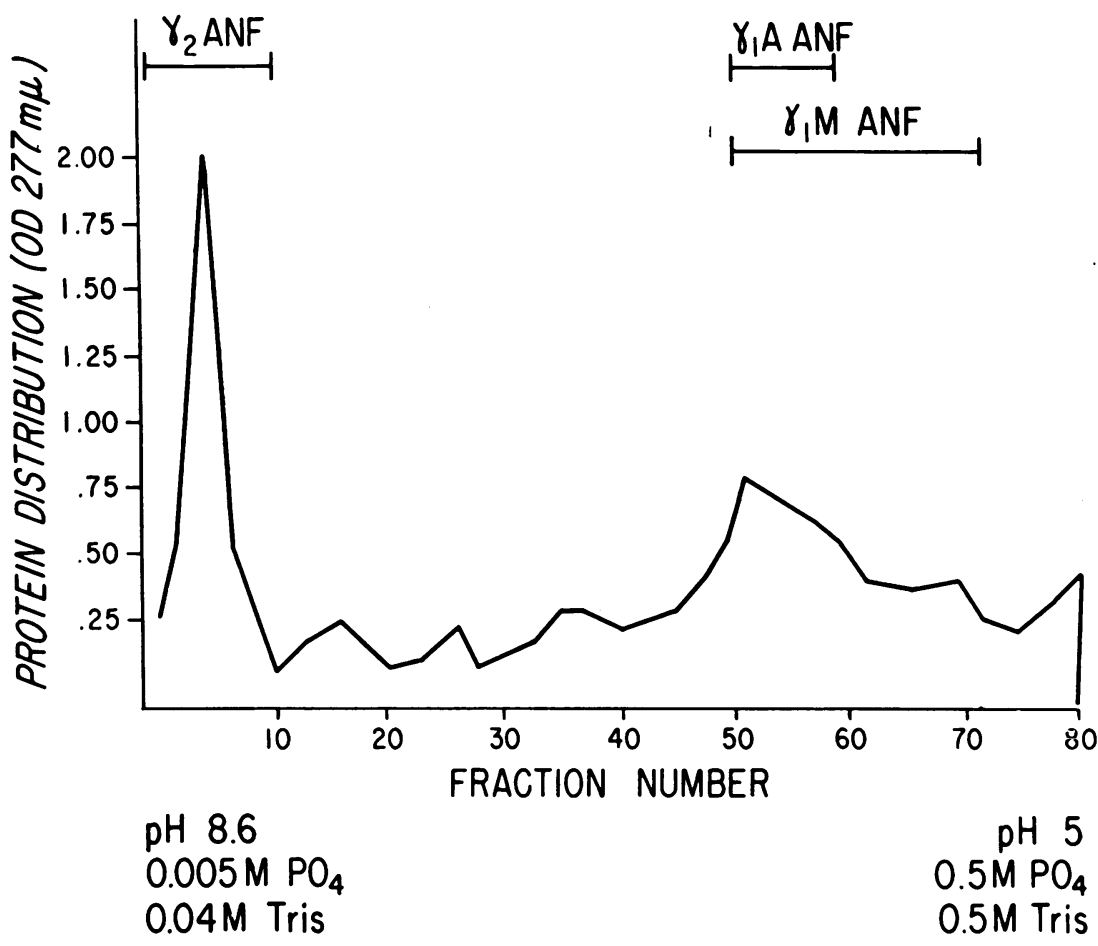

Fig. 2. DEAE-CEllulose Chromatography OF LUPUS SERUM $C_{1}$ BY continuous MOLARITY AND PH GRADIENTS.

relate with sensitivity to inactivation by $0.1 \mathrm{M}$ mercaptoethanol (Figure 3). In sera $\mathrm{K}$ and $\mathrm{L}_{1}$ where $\gamma_{1 \mathbf{A}}$ ANF sedimented as $7 \mathrm{~S}$ globulins, the titers of $\gamma_{1 \mathrm{~A}}$ ANF were not affected by mercaptoethanol treatment. In sera $S_{1}$ and $E$ where $\gamma_{1 A}$ ANF appeared to sediment, at least in part more rapidly than $7 \mathrm{~S}$ globulins, the titers of $\gamma_{1 \mathrm{~A}} \mathrm{ANF}$ were reduced by mercaptoethanol treatment.

\section{Relation of $A N F$ to $R F$}

Hall and associates (20) demonstrated that in sera from RA patients where both ANF and rheumatoid factors (RF) were present, ANF could be absorbed by histone without affecting the titer of RF. RF could be absorbed by latex particles coated with $\gamma$-globulin without affecting the titer of ANF. In our study, 16 of $17 \mathrm{LE}$ sera had measurable amounts of $\gamma_{1 \mathrm{M}}$ ANF. None of these sera had RF detectable at $1: 20$ serum dilution with the human Fr. II sensitized latex agglutination test. Since the RA sera had high titers of $\mathrm{RF}$ as well as ANF, however, it was possible that in these latter sera the titers of ANF, particularly in the $\gamma_{1 \mathrm{M}}$ class, might be falsely elevated due to interaction of $\mathrm{RF}$ and $\mathrm{ANF}$ on the nuclei. If this were so, the titers of ANF might be reduced if the $\mathrm{RF}$ were removed by absorption. Three LE sera without RF and four RA sera with latex titers of $1: 160$ to $1: 10,512$ for $R F$, were serially absorbed with normal human Fr. II, aggregated by bis-diazotized benzidine (21). The RF titers were reduced to less than $1: 20$, but the titers of ANF were unaffected in six out of the seven sera. In one serum, however, the titer of $\gamma_{1 M}$ ANF was reduced from $1: 256$ to $1: 4$ while the titers of $\gamma_{2}$ and $\gamma_{1 \mathrm{~A}}$ were unaffected. Unsuccessful attempts were made to elute ANF from the absorbing aggregated $\gamma$-globulin by acidification to $\mathrm{pH} 5$.

This experiment suggested that the titer of $\gamma_{1 \mathrm{M}}$ ANF in some RA sera might be factitiously elevated due to RF binding to $\gamma_{2}$ ANF. To test this, sera containing only $\mathrm{RF}$ were added to dilutions of three other sera in which only $\gamma_{2}$ ANF could be detected. In one of the three sera (serum K, Table II) a $\gamma_{1 \text { M }}$ ANF test appeared. Serum $K$, which was from a patient with juvenile rheumatoid arthritis, gave similar results with addition of ANF-negative RA sera $\mathrm{W}, \mathrm{A}$, and $\mathrm{H}$. 
TABLE I

Sedimentation of $\gamma_{2}, \gamma_{1 A}, \gamma_{1 M}$ antinuclear factors $(A N F)$ by sucrose gradient ultracentrifugation

\begin{tabular}{|c|c|c|c|c|c|c|c|c|c|c|c|c|c|c|c|c|}
\hline \multirow[t]{2}{*}{ Patient: } & \multirow{2}{*}{$\begin{array}{l}\text { Fraction } \\
\text { no. }\end{array}$} & \multicolumn{3}{|c|}{$\mathbf{K}$} & \multicolumn{3}{|c|}{$\mathbf{L}_{1}$} & \multicolumn{3}{|c|}{$\mathrm{D}^{*}$} & \multicolumn{3}{|c|}{$S_{1}$} & \multicolumn{3}{|c|}{ E } \\
\hline & & $\gamma_{2}$ & $\gamma_{1 \mathbf{A}}$ & $\gamma_{1 M}$ & $\gamma_{2}$ & $\gamma_{1 \mathbf{A}}$ & $\gamma_{\mathbf{M M}}$ & $\gamma_{2}$ & $\gamma_{1 \mathrm{~A}}$ & $\gamma_{\mathbf{M}}$ & $\gamma_{2}$ & $\gamma_{1 \mathbf{A}}$ & $\gamma_{1 M}$ & $\gamma_{2}$ & $\gamma_{1 \mathbf{A}}$ & $\gamma_{1 M}$ \\
\hline Bottom & $\begin{array}{l}1 \\
2 \\
3 \\
4 \\
5 \\
6 \\
7 \\
8 \\
9\end{array}$ & $\begin{array}{l}3+t \\
3+ \\
3+ \\
1+\end{array}$ & $\begin{array}{l}3+ \\
3+ \\
1+ \\
1+\end{array}$ & $\begin{array}{l}+ \\
2+ \\
2+ \\
4+ \\
4+\end{array}$ & $\begin{array}{l}1+ \\
4+ \\
4+ \\
1+\end{array}$ & $\begin{array}{l}1+ \\
4+ \\
1+\end{array}$ & $\begin{array}{l}1+ \\
2+ \\
2+ \\
4+ \\
3+\end{array}$ & $\begin{array}{l}1+ \\
2+ \\
1+ \\
1+\end{array}$ & $\begin{array}{l}1+ \\
4+ \\
4+\end{array}$ & & $\begin{array}{l}1+ \\
4+ \\
4+ \\
4+ \\
1+\end{array}$ & $\begin{array}{l}2+ \\
2+ \\
1+\end{array}$ & $\begin{array}{l}1+ \\
4+ \\
2+\end{array}$ & $\begin{array}{l}2+ \\
2+ \\
4+\end{array}$ & $\begin{array}{l}1+ \\
3+ \\
1+\end{array}$ & $\begin{array}{l}1+ \\
2+ \\
4+ \\
4+ \\
2+\end{array}$ \\
\hline
\end{tabular}

* Patient with definite rheumatoid arthritis (RA), stage IV, class III, onset at age 12 with disease activity for 25 years. $\gamma_{2}$ ANF titer $1: 4 ; \gamma_{1 A}, 1: 64 ; \gamma_{1 M}, 1: 4$, not included in Figure 3 . Patients $K, L_{1}, S_{1}$, and $E$ are shown in Figure 4.

$\dagger 4+$, more than $75 \%$ of the nuclei in a field brightly fluoresce; $3+, 50$ to $75 \%$ of the nuclei fluoresce; $2+, 25$ to $50 \%$ of the nuclei fluoresce; $1+$, up to $25 \%$ of the nuclei fluoresce. Fractions giving $3+$ or $4+$ nuclear fluorescence give positive ANF when diluted 1:10. The titer of fractions giving $1+$ or $2+$ nuclear fluorescence was $1: 10$. Sera from Patients $L_{1}$ and $S_{1}$ were placed in adjacent cups of the SW39L rotor and centrifuged for the same period.

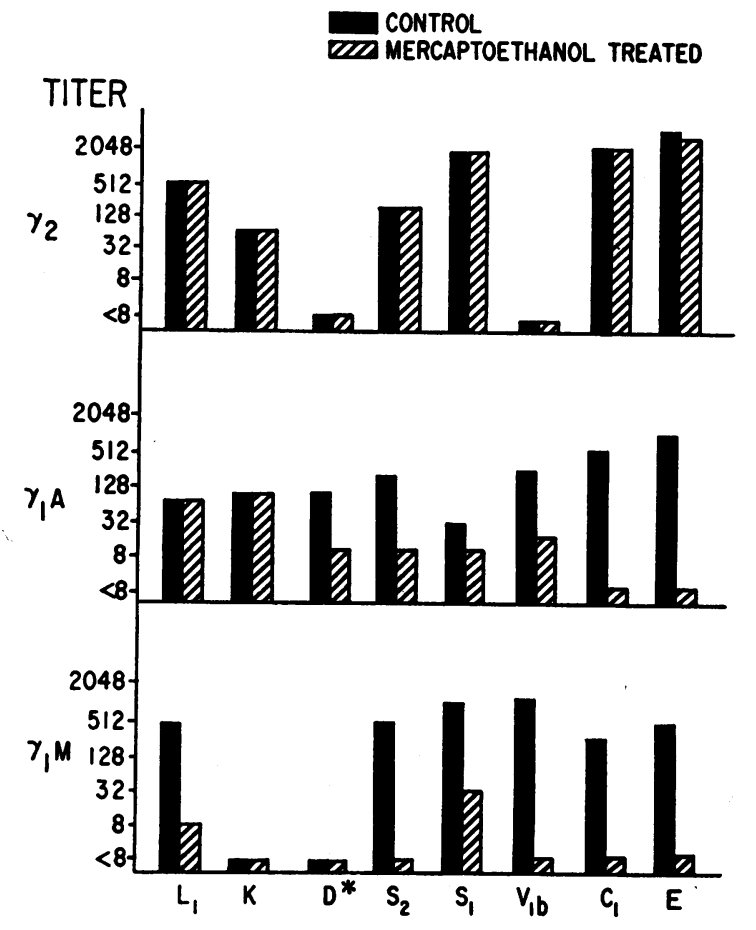

Fig. 3. Sensitivity tó inactivation by 0.1 M MerCAPTOETHANOL OF ANF OF THE THREE IMMUNOGLOBULIN CLASSES IN FIVE LE AND THREE RA SERA.

* Patient with definite RA, stage IV, class III, onset at age 12 with disease activity for 25 years. $\gamma_{2}$ ANF titer $1: 4 ; \gamma_{1 A}, 1: 64 ; \gamma_{1 \mathbf{M}}, 1: 4$ not included in Figure 3 . Other tests on these sera are shown in Figures 4 and 5. The titers of ANF are within one or two tubes in all experiments. Serum $V_{1} b$ is not shown in Figure 5 but was obtained from Patient $V_{1}$ on a date 10 months later than signified in Figure 5.
The two other sera used as sources of $\gamma_{2}$ ANF were from adult $L E$ patients $A$ and $M_{1}$. Serum $M_{1}$ (Figure 4) was diluted $1: 16$, and serum $A$ was used undiluted. They exhibited no ANF by $\gamma_{1 M}$ antiserum after mixing with the same three RA sera that had been used above. Apparently only in selected instances will RF complex with $\gamma_{2} \mathrm{ANF}$ to be detected as though there were $\gamma_{1 \mathrm{M}}$ ANF. This may well depend on specificity of RF for particular $\gamma$-globulins (i.e., $\mathrm{Gm}$ specificity) (22) or on denaturation of $\gamma_{2}$ ANF globulins. Possibly, therefore, in some RA sera, three-layer ANF tests using specific anti- $\gamma_{1 M}$ antisera detect not only $\gamma_{1 M}$ ANF but also $\gamma_{1 M}$ RF complexed to $\gamma_{2}$ ANF.

\section{Specificity for different nuclear materials}

Sera from five adult RA, one juvenile RA, and four LE patients were tested on cells treated with enzymes to assess the specificities of ANF of the different classes. DNAse treatment abolished the reactivity of the nuclei with all the ANF of all but two of the ten sera. In one of these two sera (Patient B, Table III) $\gamma_{1 \mathrm{M}}$ activity persisted, but the fluorescent nuclei were fewer and not so bright as with control slides. In the other serum ( $\mathrm{Pa}$ tient V), ANF activity persisted in all immunoglobulin classes, but the number of nuclei staining and the intensity of staining was reduced by DNAse and possibly RNAse treatment. Thus, some of the ANF present in the sera of Patients $B$ and $V$ apparently bind to nuclear material not 
TABLE II

In vitro combination of $\gamma_{2} A N F$ with rheumatoid factor*

\begin{tabular}{|c|c|c|c|c|c|c|}
\hline \multirow{2}{*}{$\begin{array}{l}\text { Dilution } \\
\text { of serum }\end{array}$} & \multicolumn{3}{|c|}{$\begin{array}{l}\text { ANF of serum } K \text {, } \\
1: 2 \text { with control } \\
\text { serum }\end{array}$} & \multicolumn{3}{|c|}{$\begin{array}{l}\text { ANF of serum } K_{1} \text {, } \\
1: 2 \text { with } R A \\
\text { serum } W\end{array}$} \\
\hline & $\gamma_{2}$ & $\gamma_{1 \mathrm{~A}}$ & $\gamma_{1 M}$ & $\gamma_{2}$ & $\gamma_{1 A}$ & $\gamma_{1 M}$ \\
\hline $1: 4$ & + & - & - & + & - & + \\
\hline $1: 40$ & + & - & - & + & - & + \\
\hline $1: 160$ & - & - & - & - & - & + \\
\hline $1: 320$ & - & - & - & - & - & + \\
\hline $1: 640$ & - & - & - & - & - & - \\
\hline
\end{tabular}

$*+=$ positive ANF test; $-\overline{=}$ negative ANF test. RA serum W shown to have no detectable ANF. The dilution of serum $\mathrm{K}$ shown was mixed with an equal volume of RA serum $W$ and incubated for 18

entirely sensitive to the action of DNAse. $\mathrm{Pa}$ tient $M_{3}$ 's $\gamma_{1 \Delta}$ and $\gamma_{1 M}$ ANF did not bind to trypsin-treated leukocyte nuclei or to DNAse-treated nuclei. Trypsin-treated leukocytes also gave lesser nuclear fluorescence with Patient B's $\gamma_{1 \mathbf{M}}$ ANF than did untreated nuclei. Apparently, therefore, part of the ANF in serum from Patient $B$ and all of that from $\mathrm{M}_{3}$ react with nuclear material sensitive to the action of trypsin. $\gamma_{2}, \gamma_{1 \mathrm{~A}}$, or $\gamma_{1 \mathrm{M}}$ ANF in the remaining seven sera (not shown in Table III) gave negative results with DNAsetreated nuclei and positive nuclear fluorescence

TABLE III

Specificity of $A N F$ of $\gamma_{2}, \gamma_{1 A}$, and $\gamma_{1 M}$ classes as measured by reactivity with enzyme-treated leukocyte nuclei*

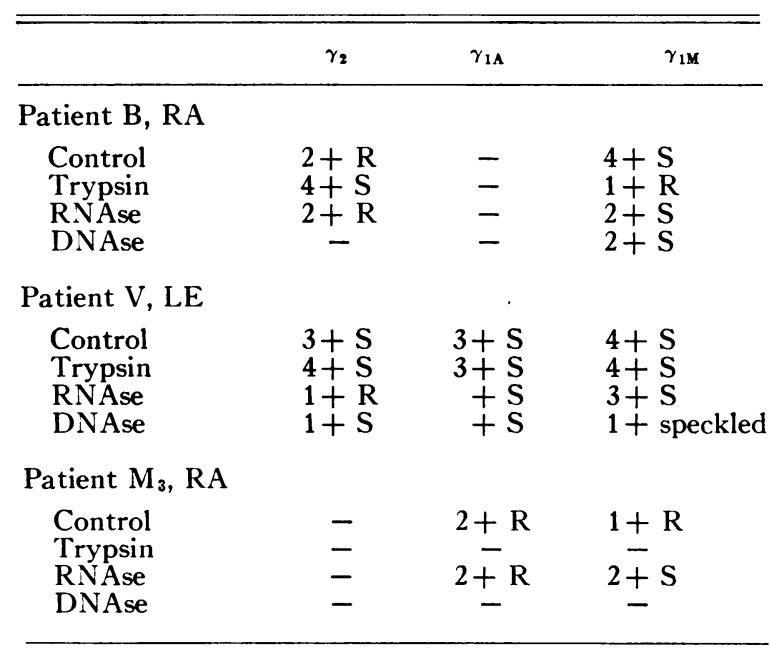

* $\mathrm{R}$ = the rims of nuclei fluoresce ; $\mathrm{S}=$ the entire "solid" nucleus fluoresces; speckled = speckled fluorescence of the nucleus. $4+$, more than $75 \%$ of the nuclei in a field brightly fluoresce; $3+, 50$ to $75 \%$ of the nuclei fluoresce; $2+, 25$ to $50 \%$ of the nuclei fluoresce; $1+$, up to $25 \%$ of the nuclei fluoresce; $-=$ negative ANF test. with control, RNAse, and trypsin-treated nuclei. Indeed, with these seven sera trypsin treatment resulted in brighter staining of more nuclei than was seen in the control slides. The possibility may be considered that trypsin treatment may make nuclear membranes more permeable to ANF directed primarily against nontrypsin-sensitive intranuclear materials.

\section{LE cell preparations}

LE cell preparations were positive in 14 of the 17 LE patients with ANF detected by the immunofluorescent tests. Of the $18 \mathrm{RA}$ patients six had positive LE cell preparations; five of these had $\gamma_{2}$ ANF of four or greater. Only one of nine RA patients with $\gamma_{2}$ ANF of less than four had a positive LE cell preparation $(\mathrm{p}<0.01)$.

\section{Three-layer $A N F$ test in $L E$ and $R A$}

High titers of ANF activities were frequent in all three immunoglobulin classes in sera from patients with LE. The $\gamma_{2}$ ANF titered 16 or better in 15 of the $17 \mathrm{LE}$ sera (Figure 4). There was no absolute correlation between the titers in the various immunoglobulin classes. In our clinic $27 \%$ of the RA patients have been shown to have $\mathrm{ANF}$ as detected by a two-layer indirect immunofluorescent test using a rabbit antiserum directed primarily against human $\gamma_{2}$-globulin (23). Eighteen RA sera selected on the basis of a positive twolayer ANF test were examined by the three-layer ANF test. Only four of the $18 \mathrm{RA}$ sera had $\gamma_{2}$ ANF that titered to 16 or better (Figure 5). The mean $\gamma_{2}$ titer among the RA sera was significantly $(\mathrm{p}<0.01)$ less than the mean $\gamma_{2}$ titer among the LE sera. The $\gamma_{1 M}$ ANF titers of the RA sera, however, were entirely comparable to those of the LE sera, whereas the $\gamma_{1 \mathrm{~A}} \mathrm{ANF}$, although lower in mean titer, were not significantly so at the $p<0.05$ level.

The three-layer immunofluorescent test might well be expected to detect amounts of ANF below the limits of sensitivity of a two-layer ANF test (7). Sera from 32 patients attending the hematology clinic were negative for ANF by the two-layer test (Figure 6). When tested by the three-layer test, ANF of only $\gamma_{1 M}$ class was found in four of these 32 control sera. In none of the four was the titer of $\gamma_{1 \mathrm{M}}$ greater than $1: 4$. Ten 
sera from RA patients with no ANF by the twolayer test were examined in the more sensitive three-layer test. One exhibited $\gamma_{2}$ and $\gamma_{1 \mathrm{~A}}$ ANF. Five had detectable amounts of $\gamma_{1 \mathrm{M}}$ ANF. The titers are shown in Figure 6.

\section{Clinical correlations}

Seven of the nine LE patients with disease less than 1 year had $\gamma_{2}$ ANF titers of 64 or greater, whereas only two of the eight patients with diseases more than 1 year had $\gamma_{2}$ ANF titers in this range (Figure 4 ). The eight LE sera with $\gamma_{1 \Delta}$ ANF titers of 16 or greater were from patients with clinical disease of less than 1 year's duration. Of the remaining nine patients, five had measur- able $\gamma_{1 \mathrm{~A}}$ ANF titers of $1: 4$ or less, and eight of those patients had been ill for more than 1 year $(p<0.01)$. Thus, our LE patients with symptoms of disease for less than 1 year tended to have higher titers of both $\gamma_{2}$ and $\gamma_{1 \mathrm{~A}}$ ANF. Those patients with disease of more than 1 year tended to be less severely ill; they had been on steroid or chloroquine therapy, or both, for longer periods.

In the RA patients with positive three-layer tests for ANF there was no correlation between the duration of disease and the titers of ANF of any one immunoglobulin class (Figure 5). However, these 18 sera were from RA patients with severe deforming and debilitating disease of long duration (23). They are only $27 \%$ of the group
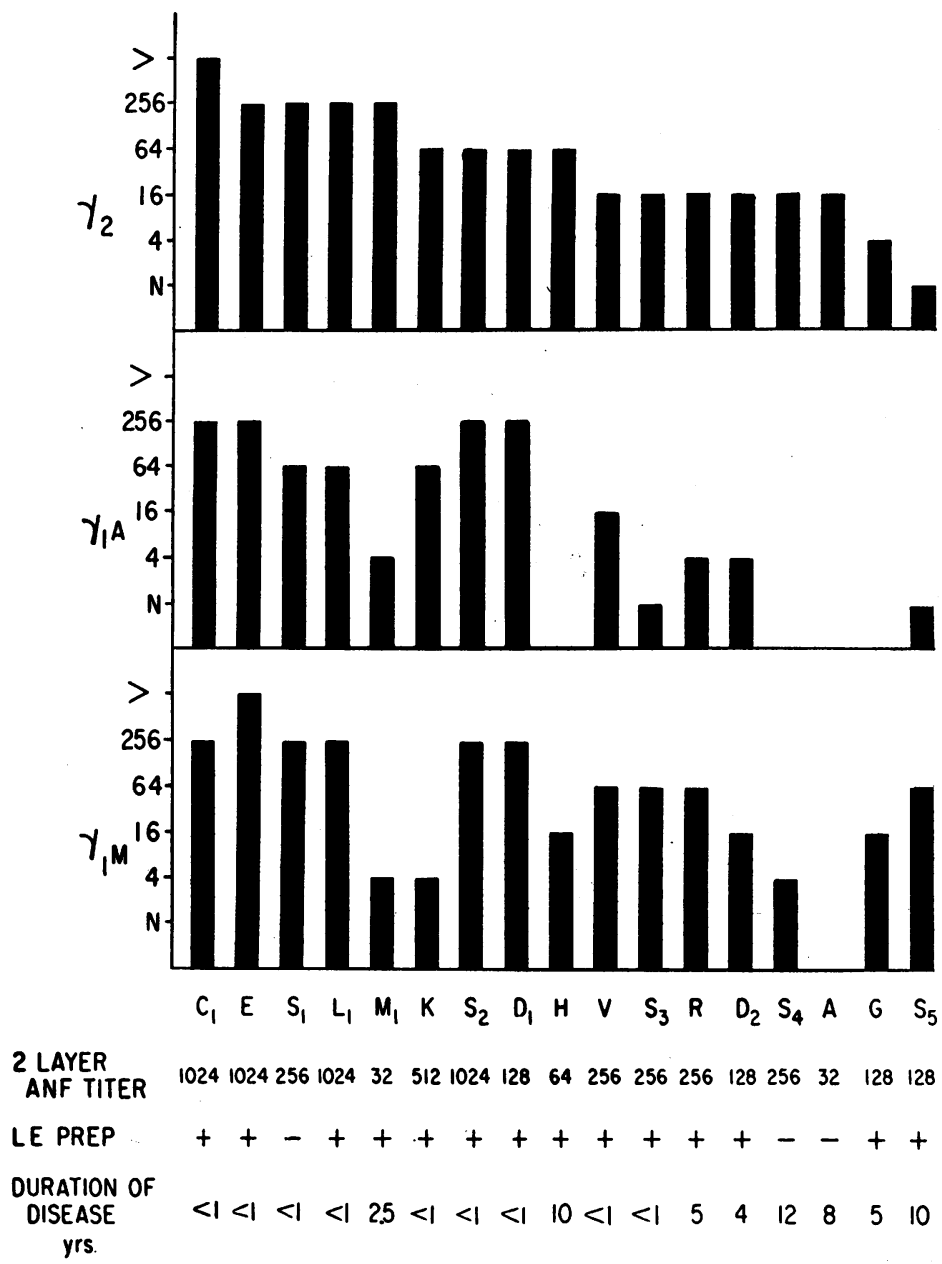

Fig. 4: Results of three-LAyer ANF tests of 17 LE SERA COMPARED WITH THE RESULTS OF ROUTINE TWO-LAYER ANF TESTS, LE CELL PREPARATIONS, AND THE DURATION OF DISEASE IN THE SAME Patients. $\mathrm{N}=$ undiluted serum. 


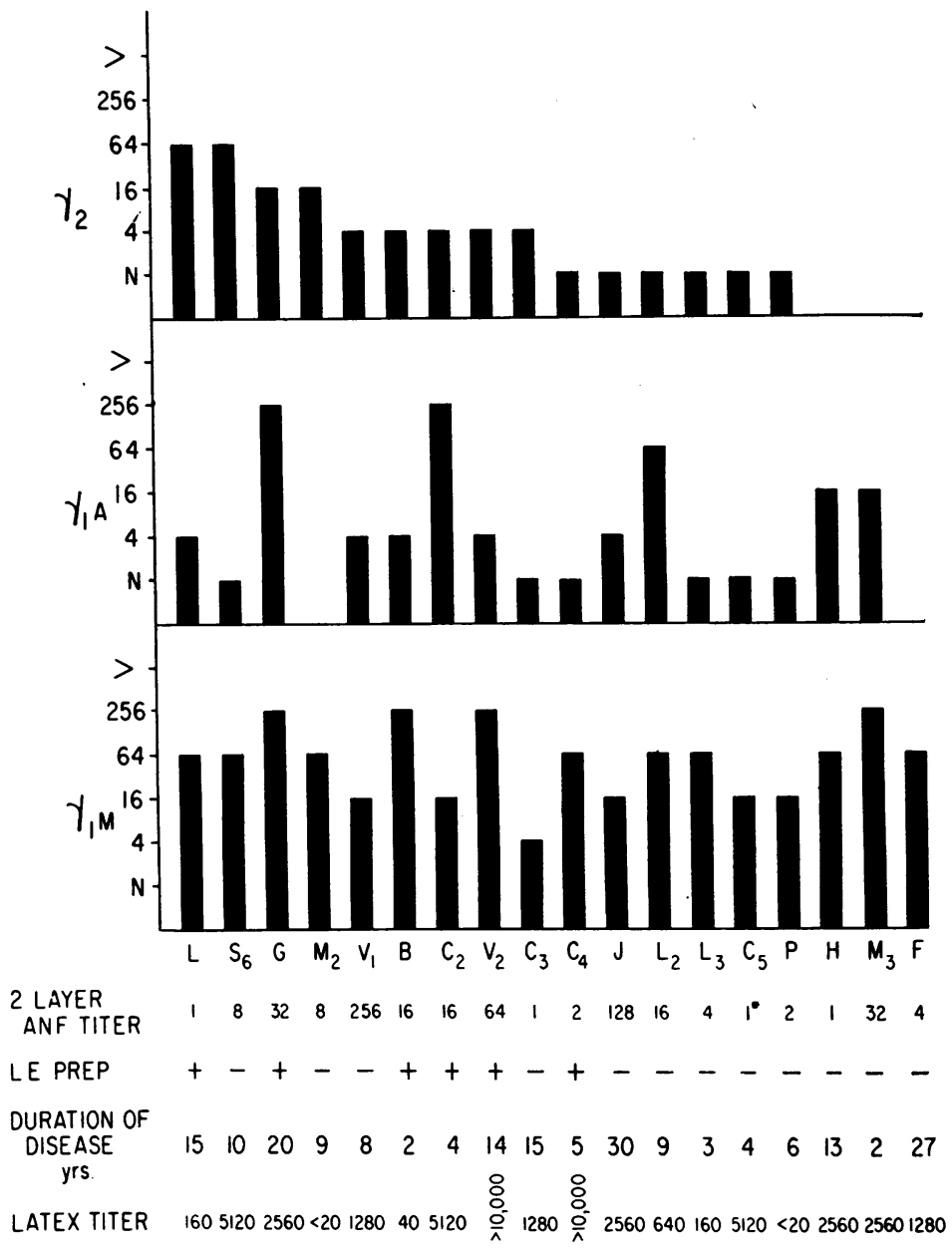

Fig. 5. Results of three-LAYer ANF test OF 18 RA SERA COMPARED WITH THE RESULTS OF ROUTINE TWO-LAYER ANF TESTS, LE CELL PREPARATIONS, DURATIONS OF DISEASE, AND THE TITERS OF RF.

* The two-layer ANF test was negative on the usual peripheral smears but was positive on peripheral smears made with blood shaken with glass beads so as to provide more damaged leukocyte nuclei (28).

of RA tested, the rest being negative in the twolayer test and from patients generally with less severe disease and of shorter duration. Ten such RA sera with negative two-layer tests were tested in the three-layer ANF test (Figure 6). Five of these with disease of somewhat longer duration had detectable amounts of ANF.

\section{Discussion}

A three-layer indirect immunofluorescent technique was adopted to measure the amounts of $\gamma_{2}$, $\gamma_{1 \mathrm{~A}}$, and $\gamma_{1 \mathrm{M}}$ ANF in human sera. The specificity of the method is dependent on the specificity of the specific rabbit antisera used in the test. Others have shown that such antisera give mono-specific lines of precipitation in gel with their homologous antigens (17-19). The antisera used here were also shown to be specific by this method and in addition by the more sensitive method of passive cutaneous anaphylaxis in guinea pig skin (8). Furthermore, the specificity of the test was corroborated by specific blocking and absorption experiments with the immunofluorescent technique. ANF were detected in all three immunoglobulin classes and were found to elute from DEAE cellulose columns as previously described for the various $\gamma$-globulins (17). 


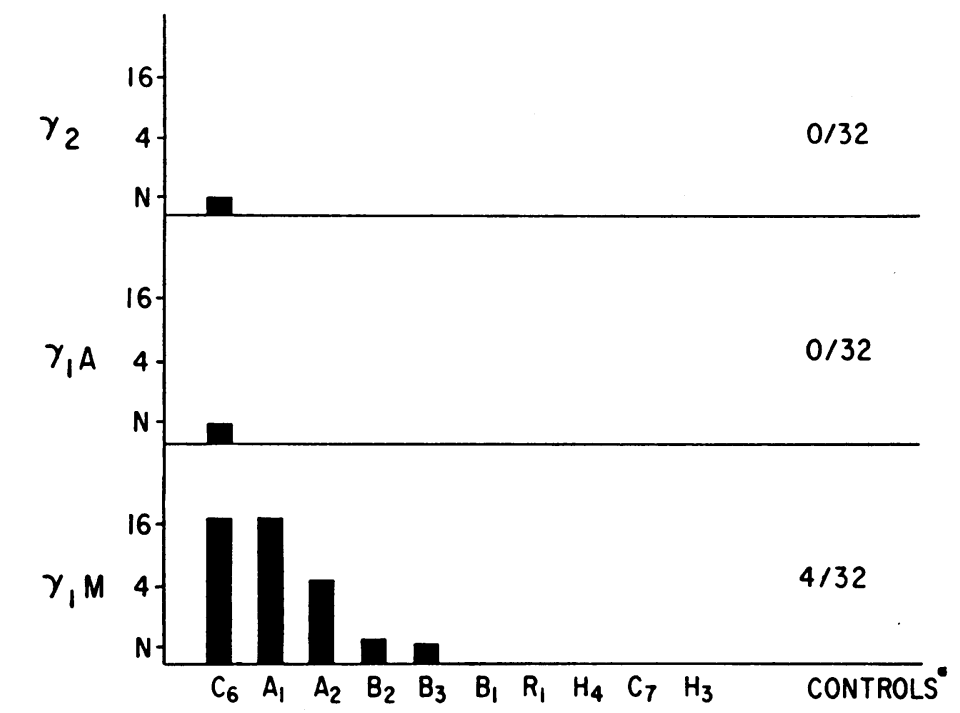

DURATION OF DISEASE $\begin{array}{lllllllllll}\text { YEARS } & 3 & 10 & 15 & 14 & 13 & 14 & 4 & 4 & 4 & 1\end{array}$

LATEX TITER $50080<20160640406402,560160160$

Fig. 6. RESUlts OF THREE-LAYER ANF teSTS OF 10 RA SERA, SELECTEd ON THE BASIS OF NEGATIVE ROUTINE TWO-LAYER ANF TESTS, COMPARED WITH DURATIONS OF DISEASE AND THE TITERS OF RF.

Since anti-insulin (4), anti-Brucella, antidiphtheria (5), and antiragweed antibodies (6) have recently been described in all three immunoglobulin classes, the detection of ANF in the same classes of globulin fortified the suggestion that $\mathrm{ANF}$, too, is an antibody. The reactivity of ANF of $\gamma_{2}$ class was not affected by incubation with mercaptoethanol, whereas the reactivity of $\gamma_{1 \mathrm{M}}$ ANF was greatly reduced or abolished as is typical of other antibodies of $\gamma_{2}$ and $\gamma_{1 \mathrm{M}}$ immunoglobulin classes (12). In two sera where the $\gamma_{1 \mathrm{~A}}$ ANF sedimented as $7 \mathrm{~S}$ globulins the reactivity of $\gamma_{1 \mathrm{~A}}$ $\mathrm{ANF}$ was unaffected by mercaptoethanol. In five sera where $\gamma_{1 \mathrm{~A}}$ ANF sedimented more rapidly than $7 \mathrm{~S}$ globulins, the $\gamma_{1 \mathrm{~A}} \mathrm{ANF}$ were, at least in part, inactivated.

The specificity of ANF for particular nuclear antigens may be of pathogenetic importance. Casals, Friou, and Teague (24) have suggested that the presence of antibody to DNA is particularly correlated with illness. In seven of the ten sera tested here the ANF of all three immunoglobulin classes reacted with nuclear material sensitive to DNAse but resistant to trypsin and RNAse. In one case (Patient B, Table III) $\gamma_{1 \mathrm{M}}$ ANF reacted with nuclear material resistant, separately, to trypsin, DNAse, and RNAse, whereas $\gamma_{2}$ ANF in the same serum reacted with DNAse-sensitive material. Another patient, $\left(\mathrm{M}_{3}\right.$, Table III) had a serum that contained both $\gamma_{1 \mathrm{~A}}$ and $\gamma_{1 \mathrm{M}}$ ANF reactive with nuclear material sensitive to either trypsin or DNAse. Patient V with LE had a serum that contained $\gamma_{2}, \gamma_{1 \mathrm{~A}}$, and $\gamma_{1 \mathrm{M}}$ ANF which were at least in part reactive with nuclear material sensitive to neither trypsin, DNAse, nor RNAse. The speckled pattern obtained with $\gamma_{1 \mathrm{M}}$ ANF on DNAse-treated nuclei suggests that some of the ANF in this serum was directed against phosphate extractable nuclear antigen described by Holman, Deicher, and Kunkel (25) and frequently found in the sera from cases of Sjörgven's syndrome (26).

$\mathrm{RF}$ and ANF may occur together in the same human serum. Other workers (20) have shown that they behave as distinctively separate antibodies with specificity for two unrelated antigens, $\gamma_{2}$ globulin and nuclear material, respectively. Since the three-layer ANF test with an anti- $\gamma_{1 M}$ 
serum was positive in $17 \mathrm{LE}$ sera where no RF was detected, it was concluded that indeed these sera did contain $\gamma_{1 \mathrm{M}}$ molecules that behave as antibodies to the nuclei. Since a positive three-layer test for $\gamma_{1 M}$ resulted where, in one instance, $R F$ was added to $\gamma_{2} \mathrm{ANF}$ in an in vitro experiment, possibly the three-layer test may sometimes give spuriously high titers for $\gamma_{1 \mathrm{M}}$ ANF in some RA sera, where high titer RF and ANF occur together.

The serum factor responsible for the LE cell test has been described as a $7 \mathrm{~S} \gamma_{2}$ globulin (27). The relationship between ANF detected by immunofluorescence and the LE cell factors was not directly examined in this study, but positive LE cell tests in RA patients were associated with higher titers of $\gamma_{2}$ ANF. In no case, as yet, have we failed to detect $\gamma_{2}$ ANF in the serum of a patient with a positive LE cell test. This observation does not, however, exclude the presence of LE cell-inducing factors of $\gamma_{1 \mathrm{~A}}$ or $\gamma_{1 \mathrm{M}}$ class.

With the less sensitive two-layer test, others have had negative ANF tests in patients with positive LE preps (20). In our hands, the two-layer ANF test has routinely been positive whenever the LE cell test or three-layer ANF test has been positive. In one patient ( $C_{5}$ with RA, Figure 5 ) the two-layer ANF test was negative on the usual peripheral smears but was positive on peripheral smears made with blood shaken with glass beads so as to provide more damaged leukocyte nuclei, as in a case described by Svec and Kaplan (28). The negative ANF tests associated with positive LE cell tests reported by others are less likely due to this type of phenomenon, but, probably more usually, due to lesser sensitivity of the reagents used in their ANF test.

The titers of $\gamma_{2}$ ANF were found to be significantly lower in 18 selected RA patients than were found in $17 \mathrm{LE}$ patients. The median titer of $\gamma_{1 \mathrm{~A}} \mathrm{ANF}$ was lower in the RA group, but the difference between the RA and LE groups for both $\gamma_{1 \mathrm{~A}}$ and $\gamma_{1 \mathrm{M}}$ ANF was not statistically significant. Of interest was the higher titer of $\gamma_{2}$ and $\gamma_{1 \mathrm{~A}} \mathrm{ANF}$ in those LE patients with acute disease of less than 1 year than in the patients with LE for more than 1 year who were in clinical remission and had been treated with steroids and chloroquin. The RA patients that exhibited positive ANF tests constituted only $27 \%$ of the clinic population. They had a higher incidence of severe disease, disease of longer duration, and a higher incidence of rheumatoid nodules (23). From the larger group of less severely ill RA patients $(73 \%)$ with a negative ANF by the twolayer test, five with disease of longer duration of the ten selected were shown to have $\gamma_{1 \mathrm{M}}$ ANF. The biological significance of having a particular antibody in one or another immunoglobulin class or in having specificity for one or another nuclear antigen, or both, is at present a matter for speculation only. Immunization of man and animals with some foreign antigens results first in the production of $\gamma_{1 M}$ antibodies and then $\gamma_{2}$ antibodies (29). By analogy the immunoglobulin class of ANF may signify a particular stage of immunization in the disease, and the correlation between presence of the various classes of ANF and the duration of RA are suggestive of this. A prospective study is underway to test whether $\gamma_{1 \mathrm{M}} \mathrm{ANF}$ appears as an earlier serologic entity in the course of RA than do $\gamma_{2}$ or $\gamma_{1 \Delta}$ ANF.

\section{Summary}

A modification of the indirect immunofluorescent technique was employed to detect antinuclear factors (ANF) of $\gamma_{2^{-}}, \gamma_{1 \mathbf{A}^{-}}$, or $\gamma_{1 \mathbf{M}^{-}}$-immunoglobulin classes. $\gamma_{1 \mathrm{~A}} \mathrm{ANF}$ in two cases appeared to sediment as $7 \mathrm{~S}$ globulins and be resistant to sulfhydryl ( $\mathrm{SH})$ treatment, whereas in other cases, they appeared to sediment faster than $7 \mathrm{~S}$ globulins and be inactivated by the $\mathrm{SH}$ treatment. ANF and rheumatoid factors ( $R F$ ), although frequently found together in the same serum, behaved as separate serological entities, but evidence was found that in some RA sera RF may interact with $\gamma_{2}$ ANF on nuclei to give the appearance of $\gamma_{1 \mathbf{M I}}$ ANF.

ANF of all three immunoglobulin classes was detected in sera from both rheumatoid arthritis (RA) and lupus erythematosus (LE) patients. $\gamma_{2} \mathrm{ANF}$ was found in higher titer in LE than in RA sera. Among the LE sera $\gamma_{2}$ and $\gamma_{1 \mathrm{~A}}$ ANF were found in higher titer, if the sera were from patients with disease for less than 1 year. LE patients with disease for more than 1 year, who generally were also in remission and on chloroquin or steroid therapy, had lower titers of $\gamma_{2}$ and $\gamma_{1 \mathrm{~A}}$ ANF.

Among the RA sera only $27 \%$ had ANF by a 
less sensitive immunofluorescent test. Among these ANF was found in those patients who had severe disease with a median duration of 9 years. RA sera lacking ANF by a less sensitive test were from patients with less severe disease and disease of shorter duration, but of ten such patients selected for study, five with disease of somewhat longer duration proved to have low titer $\gamma_{1 M}$ ANF.

\section{Acknowledgments}

The authors thank Mrs. Elaine Dow and Mrs. Phyllis Noell for their technical assistance.

\section{References}

1. Goodman, H. C., J. L. Fahey, and R. A. Malmgren. Serum factors in lupus erythematosis and other diseases reacting with cell nuclei and nucleoprotein extracts: electrophoretic, ultracentrifugal, and chromatographic studies. J. clin. Invest. 1960, 39, 1595.

2. Baum, J., and M. Ziff. 7S and macroglobulin antinuclear fluorescence factors in systemic lupus erythematosus and rheumatoid arthritis (abstract). Arthr. and Rheum. 1962, 5, 636.

3. Fireman, P., W. E. Vannier, and H. C. Goodman. The association of skin-sensitizing antibody with the $\beta_{2} \mathrm{~A}$ globulins in sera from ragweed-sensitive patients. J. exp. Med. 1963, 117, 603.

4. Yagi, Y., P. Maier, D. Pressman, C. E. Arbesman, R. E. Reisman, and A. R. Lenzner. Multiplicity of insulin binding antibodies in human sera. Presence of antibody activity of $\gamma-, \beta_{2} \mathrm{~A}-$, and $\boldsymbol{\beta}_{2} \mathrm{M}-$ globulins. J. Immunol. 1963, 90, 760.

5. Heremans, J. F., J.-P. Vaerman, and C. Vaerman. Studies of the immune globulins of human serum. II. A study of the distribution of anti-Brucella and anti-diphtheria antibody activities among $\gamma \mathrm{SS}-$, $\gamma_{1} \mathrm{M}$ - and $\gamma_{1} \mathrm{~A}$-globulin fractions. J. Immunol. 1963, 91, 11.

6. Yagi, Y., P. Maier, D. Pressman, C. E. Arbesman, and R. E. Reisman. The presence of the ragweedbinding antibodies in the $\beta_{2} \mathrm{~A}-, \beta_{2} \mathrm{M}$ - and $\gamma$-globulins of the sensitive individuals. J. Immunol. 1963, 91, 83.

7. Coons, A. J. Fluorescent antibody methods in General Cytochemical Methods, J. F. Danelli, Ed. New York, Academic Press, 1958, vol. 1, p. 400.

8. Leddy, J. P., R. W. Hill, S. N. Swisher, and J. H. Vaughan. Observation on the immunochemical nature of red cell autosensitization in Third International Symposium of Immunopathology. Basel, S. Karger, 1963, p. 318.

9. Riesfeld, R. A., D. M. Bergenstal, and R. Hertz. Distribution of gonadotrophic hormone activity in the serum proteins of normal pregnant women and patients with trophoblastic tumors. Arch. Biochem. 1959, 81, 456.

10. Kunkel, H. G. Macroglobulins and high molecular weight antibodies in Plasma Proteins. New York, Academic Press, 1960, vol. 1, 294.

11. Barnett, E. V., G. Stone, S. N. Swisher, and J. H. Vaughan. Serum sickness and plasmacytosis. A clinical, immunologic and hematologic analysis. Amer. J. Med. 1963, 35, 113.

12. Kunkel, H. G., H. Fudenberg, and Z. Ovary. High molecular weight antibodies. Ann. N. Y. Acad. Sci. 1960, 86, 966.

13. Bardawil, W. A., B. L. Toy, N. Galins, and T. B. Bayles. Disseminated lupus erythematosus, scleroderma and dermatomositis as manifestations of sensitization to DNA-protein. Amer. J. Path. 1958, 34, 607.

14. Zinkham, W. H., and C. L. Conley. Some factors influencing the formation of L. E. cells. A method for enhancing L. E. cell production. Bull. Johns Hopk. Hosp. 1956, 98, 102.

15. A Committee of the American Rheumatism Association. Primer on the rheumatic diseases, parts I and II. J. Amer. med. Ass. 1959, 171, 1205, 1345.

16. Steinbrocker, O., C. H. Traeger, and R. C. Batterman. Therapeutic criteria in rheumatoid arthritis. J. Amer. med. Ass. 1949, 140, 659.

17. Vaerman, J.-P., J. F. Heremans, and C. Vaerman. Studies of the immune globulins of human serum. I. A method for the simultaneous isolation of the three immune globulins ( $\gamma \mathrm{SS}, \gamma 1 \mathrm{M}, \gamma 1 \mathrm{~A})$ from individual small serum samples. J. Immunol. 1963, 91, 7.

18. Fahey, J. L., and C. McLaughlin. Preparations of antisera specific for $6.6 \mathrm{~S} \gamma$ globulins, $\beta_{2} \mathrm{~A}$-globulins, $\gamma_{1}$-macroglobulins, and for type I and II common $\gamma$-globulin determinants. J. Immunol. 1963, 91, 484.

19. Mellors, R. C., and L. Korngold. The cellular origin of human immunoglobulins $(\gamma 2, \gamma 1 \mathrm{M}, \gamma 1 \mathrm{~A})$. J. exp. Med. 1963, 118, 387.

20. Hall, A. P., W. A. Bardawil, T. B. Bayles, A. D. Mednis, and N. Galins. The relation between the antinuclear, rheumatoid and L. E.-cell factors in the systemic rheumatic diseases. New Engl. J. Med. 1960, 263, 769.

21. Butler, V. P., and J. H. Vaughan. A study of rheumatoid factor reactions with animal gamma globulins. Submitted to J. exp. Med.

22. Grubb, R. Agglutination of erythrocytes coated with "incomplete" anti-RH by certain rheumatoid arthritic sera and some other sera. Acta path. microbiol. scand. 1956, 39, 195.

23. Condemi, J. J., E. V. Barnett, E. C. Atwater, E. S. Mongan, R. F. Jacox, and J. H. Vaughan The significance of antinuclear factors in rheumatoid arthritis (abstract). Arthr. and Rheum. 1963, 6, 266. 
24. Casals, S. P., G. J. Friou, and P. O. Teague. Specific nuclear reaction pattern of antibody to DNA in lupus erythematous sera. J. Lab. clin. Med. 1963, 62, 625.

25. Holman, H. R., H. R. G. Deicher, and H. G. Kunkel. The L. E. cell and the L. E. serum factors. Bull. N. Y. Acad. Med. 1959, 35, 409.

26. Beck, J. S. Variations in the morphological patterns of "autoimmune" nuclear fluorescence. Lancet 1961, 1, 1203.
27. Fallet, G. H., J. Lospalluto, and M. Ziff. Chromatographic and electrophoretic studies of the L. E. factor. Arthr. and Rheum. 1958, 1, 419.

28. Svec, J. K., and M. A. Kaplan. A variant L. E. factor reactive only with "altered" nuclear material. Arthr. and Rheum. 1963, 6, 11.

29. Bauer, D. C., M. J. Mathies, and A. B. Stavisky. Sequences of synthesis of $\boldsymbol{\gamma}-1$ macroglobulin and $\gamma 2$ globulin antibodies during primary and secondary responses to proteins, Salmonella antigens, and phage. J. exp. Med. 1963, 117, 889. 